\title{
Childhood Neurocysticercosis: A Rural Teaching Hospital Experience
}

\section{Arjun Sakha Bhalla, Baljeet Maini and Bablu Kumar Gaur}

Department of Paediatrics, Maharishi Markandeshwar Institute of Medical Sciences and Research, Mullana, Ambala, India

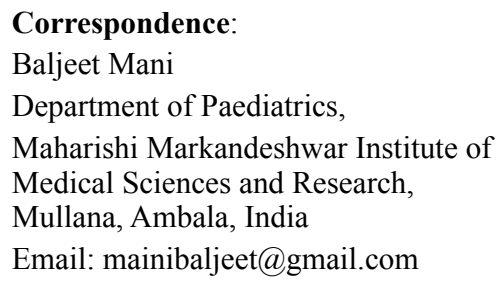

DOI: $10.3126 /$ jnps.v39i2.27425

Submitted on:2020-1-27

Accepted on: 2020-4-2

\section{Acknowledgements: None}

Funding: Nil

Conflict of Interest: None declared

Permission form IRB: Yes

To cite this article: Bhalla AS, Maini B, Gaur BK. Childhood Neurocysticersosis: A rural teaching hospital experience. $\mathrm{J}$ Nepal Paediatr Soc. 2019;39(2):65-71.

\begin{abstract}
Introduction: Neurocysticercosis (NCC) is caused by the larval stage of Taenia Solium. Neurocysticercosis is the most common cause of acquired epilepsy in developing countries. In India NCC has been identified as a significant cause of seizures.

Methods: This prospective observational study was conducted on 150 children of NCC up to 18 years of age in a tertiary care hospital. The diagnosis was based on clinical and laboratory/ radiological evaluation of the patients. Socio-clinical, radiological and serological data of the patients were analysed.
\end{abstract}

Results: A total of 150 children were enrolled in this study. The commonest age group of the cases in this study was six to 10 years. Male to female ratio was $1.8: 1$. The largest percentage of cases belonged to upper lower class $(56 \%)$ and lowest was $4 \%$ in upper class. Sixty percent subjects were non vegetarian. Seizures were the most common presentation (96\%). Headache was present in $44 \%$ cases. Single lesion was commonest type of lesion on radiological examination with frontal cortex as most commonly involved area of brain. Stage II NCC was commonest type of lesion on MRI. EEG was abnormal in 38\% cases. Serum ELISA for cysticercosis was positive in $10 \%$ cases. Number of lesions was not associated with age group, type of seizure or any particular area of brain.

Conclusion: Stage II NCC the commonest type of NCC. Single lesion NCC was more common than multiple lesions. All cases with atypical presentation and positive ELISA had multiple lesions. Frontal portion of cortex was most commonly involved.

Key words: ELISA; Neurocysticercosis; Neuroimaging

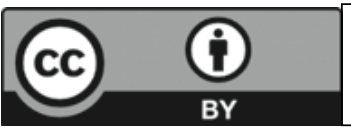

This work is licensed under creative common attribution 3.0 license 


\section{INTRODUCTION}

Taenia solium cysticercosis was added by World Health Organisation (WHO) to the list of major Neglected Tropical Diseases (NTDs) in 2010. ${ }^{1}$ Its prevalence is more common in areas of unhealthy environment. Neurocysticercosis (NCC) is now the most frequent preventable cause of epilepsy worldwide, and is estimated to cause $30 \%$ of all epilepsy cases in countries where the parasite is endemic. ${ }^{2}$ In India too, NCC has been identified as a cause of around one third of all cases of epilepsy. ${ }^{3}$

Clinical presentations are as diverse as headache, focal deficits, seizures or signs of increased intracranial pressure, papilledema, monoparesis etc. ${ }^{4-8}$ Exact clinical diagnosis is usually difficult because of the polymorphic symptomatology. Pathological confirmation of the parasite has its own hardships. ${ }^{9}$ Diagnosis at present is based on the Del Brutto's criteria. ${ }^{11}$

Various studies have been done in India and other countries on clinical and laboratory profile of NCC. ${ }^{11-13}$ Some of the features seem to be common yet they all differ in age, sex, radiological and serological findings etc. This study was an attempt to assess the clinical profile of NCC in North Indian rural children along with their radiological and serological status.

\section{METHODS}

This observational study was conducted on 150 children up to 18 years age, satisfying the criteria for definitive or probable diagnosis of NCC. ${ }^{10}$ Consent was obtained from the patients' parents before enrolling in the study. Subjects with other co-morbidities like tuberculosis, HIV, malignancy, patients presenting with pre-existing CNS morbidities, patients on immune-suppressive therapy, previous severe brain trauma and nonconsenting parents were excluded. A detailed medical history with emphasis on the description of the clinical manifestations, anthropometric measurements, general physical examination, and systemic examination, including neurological examination were performed. Socioepidemiological details (as per Kuppuswamy classification) were also recorded. ${ }^{14}$
Diagnostic evaluation was done including haemoglobin, peripheral blood smear, total and differential leukocyte counts and microscopic examination of stool. EEG was done inside hospital using Medicaid NP 2300 W (2005), machine. Stool examination for evidence of Taenia Solium infestation was done. ELISA test was performed on blood sample on Nova tec Taenia Solium IgG, TAEG0420. Contrast Enhanced Computerised tomography (CECT) scan of brain [Philips, Philips Ingenuity, Netherland (2011)] and MRI brain [Philips, Acehieva Philips 1.5 Tesla (SRN 32986), Netherland (2011)] were done inside the hospital. At the time of the initial scan, the following characteristics of the lesions were recorded: (a) No. of lesions (b) Site (c) Stage (d) Size (e) Scolex (f) Perilesional edema. Patients were followed up every month for initial one year of treatment.

All data were recorded in Microsoft Excel sheet and transported to SPSS version 23.0. Frequency and percentages were worked out to find the distribution of the respondents according to sociopersonal characteristics. Chi square test was applied to test the statistical significance of proportions. Other tests were employed as relevant. Level of significance was kept at $5 \%$.

\section{RESULTS}

Six to 10 years age group was the most affected age group (38\%). Out of 150 children included in the study, $96(64 \%)$ were males and $54(36 \%)$ were females. NCC was predominant in upper lower class $(56 \%)$ followed by lower middle class $(30 \%)$. (Table 1).

Maximum number of seizure cases, 96 (64\%), were generalised tonic clonic seizure (GTCS) type, 48 (32\%) cases had focal seizures and six (4\%) presented with other manifestations. Twenty four cases $(16 \%)$ had status epilepticus as initial presentation. Papilledema was present in six (4\%) cases. All the cases who had papilledema had multiple lesions. Headache was present in $66(44 \%)$ cases (table 2). Table 3 shows that 57 cases (38\%) were having abnormal EEG. Fifteen cases (10\%) were seropositive on ELISA test. Sixty eight percent patients had single lesion on radiological evaluation and scolex was visualised in $84 \%$ of 
Table 1. Demographic profile of study patients

\begin{tabular}{|c|c|}
\hline & Number of cases $(\%)$ \\
\hline \multicolumn{2}{|l|}{ Age } \\
\hline 0 to 5 years & $9(6 \%)$ \\
\hline 6 to 10 years & $57(38 \%)$ \\
\hline 11 to 15 years & $54(36 \%)$ \\
\hline 16 to 18 years & $30(20 \%)$ \\
\hline \multicolumn{2}{|l|}{ Sex } \\
\hline Female & $54(36 \%)$ \\
\hline Male & $96(64 \%)$ \\
\hline \multicolumn{2}{|l|}{$\begin{array}{l}\text { Kuppuswami } \\
\text { Socioeconomic scale }\end{array}$} \\
\hline Upper & $6(4 \%)$ \\
\hline Upper middle & $15(10 \%)$ \\
\hline Lower middle & $45(30 \%)$ \\
\hline Lower & $84(56 \%)$ \\
\hline
\end{tabular}

patients on initial assessment. Stage II was the most predominant type whereas $36(25 \%)$ patients had multiple stages at initial diagnosis.

We analysed the association of single/multiple lesions in brain with factors like age, gender, type of seizure and site of lesion. None of these factors were significantly related to number of lesions. Positive serology (ELISA) was significantly associated with multiplicity of lesions (Table 4). We also analysed association of factors like age, gender and number of lesions (MRI) with seizure type. Table 5 shows that none of these factors were linked to any seizure type.

\section{DISCUSSION}

NCC is one of the serious problems of public health in India. This nation is one of the endemic regions for Taenia Solium, hence the neurocysticercosis too is highly prevalent. This entity presents with varying signs and symptoms in both children. Present study was done with an aim of observing the clinical, serological and radiological features of childhood NCC in North Indian rural population.

In this study most of the patients belonged to low earning sections of population, namely upper lower
Table 2. Distribution of patients according to clinical presentation

\begin{tabular}{|r|r|}
\hline & Number of cases (\%) \\
\hline Type of presentation & \\
\hline Focal seizures & $48(32 \%)$ \\
\hline GTCS & $96(64 \%)$ \\
\hline Headache & $66(44 \%)$ \\
\hline Seizure duration & 120 \\
\hline$<30$ minutes & 24 \\
\hline$>30$ minutes & 6 \\
\hline No Seizure & $6(4 \%)$ \\
\hline Papilledema & \\
\hline
\end{tabular}

class $(56 \%)$ followed by lower middle class $(30 \%)$. Only one case of NCC belonged to upper middle class. Our study results are thus in agreement with available literature on the epidemiology of NCC. Overall, age group most affected was six to 15 years. This age group is exposed to contaminated food sources more than the $<$ five years age groups. The number of patients $>15$ years in our study was small. Unhealthy feeding practice like eating street food is high in bigger age groups, which is easily available (and mostly unregulated in countries like India) and predisposes to a lot of health issues, including NCC.

Our study results are in agreement with the natural life cycle of Taenia Solium which has the possibility of being spread by contaminated food sources, both vegetarian (e.g. raw eaten leafy vegetables which are improperly cleaned) and non vegetarian (undercooked infested pork). In this study, where majority of people follow mixed pattern of diet, $40 \%$ cases were pure vegetarians. Yashodhara $\mathrm{P}$ et al. in Indian state of Andhra Pradesh also noticed that there is similar distribution of NCC in vegetarians and nonvegetarians. ${ }^{16}$ In a study in northern state of Uttrakhand in India, the cases were mostly vegetarian. ${ }^{17}$ Cysticercosis is a disease of poor food hygiene and sanitation regardless of eating preferences. ${ }^{15-17,21}$ 
Table 3. Distribution of patients according to EEG

\section{Frequency Percentage}

\section{EEG}

Normal EEG
Abnormal EEG

$93 \quad 62 \%$

ELISA (IgG)

Positive

Number of lesions

Single Lesion

Site of brain involved

Parietal cortex

Temporal cortex

Occipital cortex

Multiple lesions

Other portions of brain

\section{Stages of NCC}

$\begin{array}{ccc}\text { I } & 12 & 8 \% \\ \text { II } & 51 & 34 \% \\ \text { III } & 30 & 20 \% \\ \text { IV } & 21 & 14 \% \\ \begin{array}{l}\text { Multiple Stages present } \\ \text { in brain } \\ \text { Scolex visualised }\end{array} & 36 & 24 \% \\ & & 84 \%\end{array}$

Seizures (96\%) and headache (44\%) were the most common presentation of NCC in this study. A higher incidence of seizures is reported in published studies from India than from other countries. In this study generalised seizures (64\%) were more common than partial seizures $(32 \%)$. Other studies from India have also shown similar findings. ${ }^{18-20}$ In a study from Nepal by Basu $\mathrm{S}$ et al., focal seizure was predominant $(70.7 \%)$ seizure type. ${ }^{21}$ Available literature thus shows a mixed pattern of predominant clinical seizure type in NCC. Types of seizure are generally dependent on quantitative neurological defect, their location and other individual factors. In this study, GTCS type of seizure was significantly associated with status epilepticus. Other than this, there were no particular association of seizure type with other factors like
Table 4. Relationship of number of lesions (CT/MRI) and other patient factors

\begin{tabular}{|c|c|c|c|}
\hline Number of lesions & $\begin{array}{l}\text { Single } \\
\text { (n) }\end{array}$ & $\begin{array}{l}\text { Multiple } \\
\text { (n) }\end{array}$ & p Value \\
\hline \multicolumn{4}{|l|}{ Age (years) } \\
\hline 0 to 5 & 6 & 3 & 0.89 \\
\hline 6 to 10 & 42 & 15 & \\
\hline 11 to 15 & 36 & 18 & \\
\hline 16 to 18 & 18 & 12 & \\
\hline \multicolumn{4}{|l|}{ Sex } \\
\hline Male & 63 & 33 & \\
\hline Female & 39 & 15 & \\
\hline \multicolumn{4}{|l|}{ Type of seizure } \\
\hline GTCS & 69 & 27 & 0.10 \\
\hline Focal & 33 & 15 & \\
\hline Other manifestation & 0 & 6 & \\
\hline \multicolumn{4}{|l|}{ Site of lesion } \\
\hline Frontal & 45 & 15 & 0.09 \\
\hline Parietal & 21 & 9 & \\
\hline Temporal & 21 & 3 & \\
\hline Occipital & 9 & 3 & \\
\hline $\begin{array}{l}\text { Multiple portion of } \\
\text { cortex }\end{array}$ & 6 & 12 & \\
\hline $\begin{array}{l}\text { Other portions of } \\
\text { brain }\end{array}$ & 0 & 6 & \\
\hline ELISA positivity & 3 & 12 & 0.02 \\
\hline
\end{tabular}

age, sex, number of lesions and dietary pattern of the patients. Nearly $44 \%$ of patients were having headache as one of the presenting symptoms. Similar findings have been reported in many such studies. ${ }^{6,19-21}$ In a study done by Bhattacharjee et al., $63 \%$ cases had headache. ${ }^{15}$ Papilledema was seen in only six cases (4\%) in present study. Similar incidence of papilledema was reported in study done by Singhi et al. ${ }^{6}$ Semiology of presentation is determined by site and stage of lesions as also as how early the patients present to health care facility.

In this study, nearly one third cases, $(n=48)$ were having multiple lesions on radiological examination and rest of the patients with only one lesion. One 
Table 5. Relationship of patient factors associated with type of seizure

\begin{tabular}{|c|c|c|c|c|}
\hline Type of seizure & GTCS & $\begin{array}{l}\text { Focal } \\
\text { seizure }\end{array}$ & $\begin{array}{l}\text { No } \\
\text { seizure }\end{array}$ & $\begin{array}{l}p \\
\text { value }\end{array}$ \\
\hline \multicolumn{5}{|l|}{ Age } \\
\hline 0 to 5 years & 9 & 0 & 0 & 0.24 \\
\hline 6 to 10 years & 30 & 27 & 0 & \\
\hline 11 to 15 years & 33 & 15 & 6 & \\
\hline 16 to 18 years & 24 & 6 & 0 & \\
\hline \multicolumn{5}{|l|}{ Sex } \\
\hline Male & 57 & 36 & 3 & 0.52 \\
\hline Female & 39 & 12 & 3 & \\
\hline \multicolumn{5}{|l|}{$\begin{array}{l}\text { Number of } \\
\text { Lesions }\end{array}$} \\
\hline Single & 69 & 27 & 0 & 0.10 \\
\hline Multiple & 27 & 21 & 6 & \\
\hline No seizures & 0 & 0 & 6 & \\
\hline
\end{tabular}

case had ocular cysticercosis too, confirmed by retinal examination. Singhi et al. also reported single lesion to be the most common lesion on $\mathrm{MRI} / \mathrm{CT} .{ }^{6}$ Six cases who had atypical presentation, had multiple lesions. None of the single lesion patients had atypical presentation. In this study, multiple lesions were not associated with any particular age, sex, seizure type or duration and EEG abnormalities. Also multiple lesions were not associated with any particular region of the brain. Semiology of seizures and other symptoms depends on site of brain involved. ${ }^{6}$

In this study, majority (50\%) of all the lesions were cystic in nature followed by calcified lesion (24\%). Stage II NCC was most prevalent in our study. Other authors also report this type of radiological lesion to be the commonest finding. ${ }^{6,15,19-20}$ In this study, scolex was visible in $84 \%$ of cases. Singhi et al. also reported similar finding in their study. ${ }^{6}$ Other authors have reported varying rates of scolex visualisation. ${ }^{15}$ Scolex visualisation is generally better with MRI as compared with CT. Differing rates of scolex visualisation in different studies may be because of different radiological modalities in various centres, used for diagnosis. With more availability and advancement of MRI, more cases are being detected these days.

No immunological test has been developed till now, which is very sensitive or specific for NCC. ELISA as a serological evidence has been labeled as a minor criteria in diagnostic categorisation. In a study by Kotokey et al. in Assam, (north east India) $78.4 \%$ cases were ELISA positive. ${ }^{21}$ Sahu PS et al. have found anti cysticercus IgG ELISA positive in $28.1 \%$ of patients. ${ }^{22}$ In our study, only $10 \%$ (15 cases) had ELISA sero positivity for NCC. Singhi et al., similarly reported ELISA positivity in only $15.8 \%$ cases. Authors also raised the doubt about its usefulness as a diagnostic criterion in an endemic country like India. ${ }^{6}$ All the 15 cases who were ELISA positive in present study had multiple radiological lesions. However, out of all the 102 patients having multiple lesions, 87 had negative seroreactivity. The type of serological test in different studies is different, thereby explaining non uniformity of the results. In a recent review by Carpio et al., the usefulness of currently available antibody detection serological tests has been doubted and new tests based on antigen detection particularly in CSF may hold high diagnostic value. ${ }^{24}$ Moreover, with current advancement in MRI brain, the utility of serology in diagnosis of NCC is likely to dwindle. We did not employ CSF serology as diagnostic modality.

There is large variability of EEG findings in NCC in available literature. In this study, 57 (38\%) cases had abnormal EEG pattern. Similar results were reported by other authors. ${ }^{15}$ In contrast to this, Singhi $\mathrm{P}$ et al. reported more EEG abnormalities (focal epileptic in $54.9 \%$ and generalised abnormalities in $13.7 \%) .{ }^{6}$ In general, there are no EEG abnormalities in many cases of seizure patients. In a study by Singh RD et al. authors reported 51\% normal EEG in generalised seizure patients and $42 \%$ normal EEG in focal seizure patients. ${ }^{24}$ Chayasirisobhon $\mathrm{S}$ et al. reported that the EEG abnormalities in NCC may be influenced by location and stage of lesion. ${ }^{25}$ Technical aspects are quite different interpreting paediatric EEG needing special expertise, which also may be the reason for these contrasting results of various studies. 
In today's scenario, huge stress is being laid by the Government of India, probably for the first time on such a large scale as present, on use of toilets and shunning open defecation. It is expected that if toilet use is largely adopted in rural areas, problems like NCC will diminish. It is imperative that government should strictly enforce the food sanitation laws too to curb various illnesses alongside promotion of toilet use for defecation. Education of public on a large scale in this age of digital media (being available in almost every hand now) can also bring down acquisition of faeco-oral infections and infestations. We recommend more community-based studies to test the utility of ELISA in diagnosing NCC. More training of interpreting EEG of children is required to bring more meaning to information on this subject. This study highlighted the clinical and laboratory features of hospitalised NCC patients only. Exact burden in a given region, though can be studied by large community based studies. The present study definitely is a reflection of sufferings and morbidities of this 'worm in brain'.
Our study has some limitations. This is a single centric study which could have led to bias in the outcome. Almost all children belonged to rural areas so we can't comment for urban childhood NCC. In our study only serum ELISA was done. Interpretation of CSF ELISA was not done in this study.

\section{CONCLUSIONS}

Majority of cases of NCC belonged to lower socio economic strata of society. Stage II NCC and single lesion NCC were the most common types of presentation on MRI brain. Frontal portion of the cortex was the most commonly involved part of brain. All cases with atypical presentation and positive ELISA test had multiple lesions. More than half of study population had normal EEG.

\section{REFERENCES}

1. W.H.O. Neglected tropical diseases: Cysticercosis: Taeniasis. April 2017. Available from: https://www.who.int/ features/factfiles/neurocysticercosis/en.

2. Montano SM, Villaran MV, Ylquimiche L, Figueroa JJ, Rodriguez S, Bautista CT, et al. Neurocysticercosis: association between seizures, serology and brain CT in rural Peru. Neurology 2005; 65:229- 33. DOI: 10.1212/01.wnl.0000168828.83461.09

3. Rajshekhar V, Raghava MV, Prabhakran V, Oommen A, Muliyil J. Active epilepsy as an index of burden of neurocysticercosis in Vellore district, India. Neurology. 2006;67:2135-139. DOI.org/10.1212/01.wnl. 0000249113.11824 .64

4. Patil TB, Paithankar MM. Clinico-radiological profile and treatment outcomes in neurocysticercosis: a study of 40 patients. Ann Trop Med PH. 2010;3(2):58-63. DOI:10.4103/1755-6783.77186

5. Prasad KN, Prasad A, Verma A, Singh AK. Human cysticercosis and Indian Scenario. J Biosci. 2008;33:571-82. DOI: https://DOI.org/10.1007/s12038-008-0075-y

6. Singhi P, Ray M, Singhi S, Khandelwal N. Clinical spectrum of 500 children with neurocysticercosis and response to albendazole therapy. J Child Neurol. 2000;15:207-13 DOI:10.1177/088307380001500401

7. Garcia HH, Nash TE, Del Brutto OH. Clinical symptoms, diagnosis, and treatment of neurocysticercosis. Lancet Neurol. 2014;13(12):1202-15. DOI :10.1016/S1474-4422(14)70094-8

8. Singh G, Burneo JG, Sander JW. From seizures to epilepsy and its substrates: neurocysticercosis. Epilepsia. 2013;54:783-92. DOI: 10.1111/epi.12159

9. Lerner A, Shiroishi MS, Zee CS, Law M, Go JL. Imaging of neurocysticercosis. Neuroimaging. Clin N Am. 2012;22:659-76. DOI: 10.1016/j.nic.2012.05.004

10. Del Brutto OH, Nash TE, White Jr.AC, Rajshekhar V, Wilkins PP, Singh G, et al. Revised diagnostic criteria for neurocysticercosis. J Neurol Sci. 2017;372.202-10 DOI: 10.1016/j.jns.2016.11.045. 
11. Singhi P. Neurocysticercosis. Thera Adv Neurol Disord. 2011; 4(2):67-81. DOI: 10.1177/1756285610395654.

12. Yadav A, Yadav RK, Singh DK, Sharma A, Bharat K, Shukla KM. Radiological profile of neurocysticercosis in children in North India. Int J Contemp Pediatr. 2016;3(1):155-58. DOI: http://dx.doi.org/ 10.18203/2349-3291.ijcp20160150

13. Kumar A, Khan SA, Khan S, Das A, Anurag, Negi KS. A study on neurocysticercosis in the foothills of Himalayas. Int J Infect Dis. 2006;10(1):79-82. DOI: https://doi.org/10.1016/j.ijid.2005.01.005

14. Singh T, Sharma S, Nagesh S. Socio-economic status scales updated for 2017. Int J Res Med Sci. 2017;5(7): 3264-67. DOI: $10.18203 / 2320-6012 . i j r m s 20173029$

15. Bhattacharjee S, Biswas P, Mondal T. Clinical profile and follow-up of 51 pediatric neurocysticercosis cases: A study from Eastern India. Ann Indian Acad Neurol. 2013;16(4):549-55. DOI: 10.4103/0972-2327.120463

16. Yashodhara P, Elizabeth B. Clinical profile of childhood Neuro Cysticercosis. IJSR. 2015;4(1):2013-6. DOI: $10.21275 / 23197064$

17. Kumar R, Rakholia R, Arya AK. Clinical, sociodemographic, radiological profile and response to albendazole therapy in children with neurocysticercosis in Uttarakhand. J Mahatma Gandhi Inst Med Sci. 2015;20:157-62. DOI: $10.4103 / 0971-9903.164242$

18. Udani V. Pediatric epilepsy - An Indian perspective. Indian J Pediatr. 2005;72(4):309-13. DOI: 10.1007/ BF02724012

19. Verma A, Gaur KJ. The clinical spectrum of neurocysticercosis in Uttaranchal. J Assoc Physicians India. 2002; 50:1398-400. PMID: 12583469

20. Basu S, Ramchandran U, Thapliyal A. Clinical profile and outcome of pediatric neurocysticercosis: a study from Western Nepal. J Pediatr Neurol. 2007;5(1):45-52. DOI: 10.4103/0972-2327.120463

21. Kotokey RK, Lynrah KG, De A. A clinico-serological study of neurocysticercosis in patients with ring enhancing lesions in CT scan of brain. J Assoc Physicians India. 2006;54:366-70. PMID: 12583469

22. Sahu PS, Parija SC, Narayan SK, Kumar D. Evaluation of an IgG-ELISA strategy using Taenia solium metacestode somatic and excretory-secretory antigens for diagnosis of neurocysticercosis revealing biological stage of the larvae. Acta Trop. 2009;110:38-4524. DOI:10.1016/j.actatropica.2009.01.002

23. Carpio A, Fleury A, Romo ML, Abraham R. Neurocysticercosis: the good, the bad, and the missing. Expert Rev Neurother. 2018;18(4):289-301. DOI: 10.1080/14737175.2018.1451328

24. Singh RD, Suryavanshi S. A hospital based study on clinicoetiological profile of seizures in children - a Kanpur (U.P., India) experience. Int J Contemp Med Res. 2016;3(10):3003-7. DOI: http://dx.doi.org/ 10.18203/2349-3291.ijcp20190728

25. Chayasirisobhon S, Menoni R, Chayasirisobhon W, Locke GE. Correlation of electroencephalography and the active and inactive forms of neurocysticercosis. Clin Electroencephalogr. 1999;30(1):9-11. DOI: $10.1177 / 155005949903000106$ 